\title{
Wheelchair Seating: Peak Pressure Distribution in Young versus Elderly Healthy Controls
}

\author{
Marina Timm $^{1 *}$, Kersti Samuelsson ${ }^{2}$ \\ ${ }^{1}$ Center of Assistive Devices, County Council, Skövde, Sweden \\ ${ }^{2}$ Department of Rehabilitation Medicine and Department of Medical and Health Sciences, Linköping University, Linköping, \\ Sweden \\ Email: *marina.timm@vgregion.se
}

How to cite this paper: Timm, M. and Samuelsson, K. (2019) Wheelchair Seating: Peak Pressure Distribution in Young versus Elderly Healthy Controls. Open Journal of Therapy and Rehabilitation, 7, 25-34. https://doi.org/10.4236/ojtr.2019.72003

Received: February 26, 2019

Accepted: March 23, 2019

Published: March 26, 2019

Copyright (c) 2019 by author(s) and Scientific Research Publishing Inc. This work is licensed under the Creative Commons Attribution International License (CC BY 4.0).

http://creativecommons.org/licenses/by/4.0/

\section{(c) (i) Open Access}

\begin{abstract}
Background: People may use a wheelchair when they need assistance with mobility. Some users have to remain seated in their wheelchair for most of their awake time and for a lot of activities. The need for a well fitted and supportive wheelchair is important and, for those who use the wheelchair for many hours, peak pressure distribution is of interest to prevent pressure ulcers and discomfort. Aim: To describe how high local peak pressures may be distributed over risk areas for pressure ulcers in different wheelchair settings. Methods: Two groups of healthy adults were recruited (40 elderly and 30 younger individuals). Two standard models of manual wheelchairs were used together with two types of wheelchair cushions. Results: The elderly group had a higher peak pressure over the ischial tuberosity and increased posterior pelvic rotation in the shaped seat cushion. Both groups had higher peak pressure over the trochanter in the shaped seat cushion. Peak pressure was also higher over the coccyx for the elderly in the shaped seat cushion compared with the plain cushion; this was lower for the younger group. Discussion: The results indicate that age might influence the important physical prerequisites when fitting a wheelchair to an individual.
\end{abstract}

\section{Keywords}

Age, Interface Pressure, Pressure Ulcers, Prevention

\section{Introduction}

In European countries, the number of wheelchair users increases as the population grows older and health care treatment develops. In 2005, about 100,000 people used wheelchairs in Sweden, of which $80 \%$ were 80 years and older and about two-thirds were women [1]. By 2016, the number of wheelchair users in 
Sweden had at least doubled [2]. Wheelchair users, especially those who have reduced mobility, sensory impairments and who have been wheelchair users for a long time, are at risk of pressure ulcers. The percentage of pressure ulcers has remained at the same level for some years, despite various efforts at local, regional and national levels [3].

Information from one of the largest units for neurological rehabilitation in Sweden (personal communication), reports that the most common locations of pressure ulcers in the population of wheelchair users are ischial tuberosity $42 \%$, followed by coccyx $38 \%$ and trochanter $8 \%$. The remaining $12 \%$ are in other locations. Pressure ulcers can affect individuals of all ages, but the risk increases with age in combination with multiple diseases, traumas and malnutrition [3] [4] [5]. Individuals over 70 years are at a greater risk of developing pressure ulcers due to thinner and less elastic skin, less subcutaneous fat, impaired blood vessels, decreased sensory perception and impaired immune system. With increasing age, sensitivity to pain and pressure also decreases, so that the individual might not be aware of the early signs of pressure ulcer development [4] [6].

Tissue damage depends on the extent and duration of pressure and on the sensitivity of the individual and of the tissue [3] [4]. When seated, most of the body weight is distributed over a relatively small area [3] [7]. In a paralysed individual, the pressure on the ischial tuberosity is particularly intense and local because small conscious or unconscious movements that could restore blood flow to the tissue are lacking [4] [8] [9] [10] [11]. Individuals with a spinal cord injury, multiple sclerosis or brain injury/stroke who have impaired sensation, muscle fatigue/paralysis, impaired mobility and cognitive problems have an increased risk of developing pressure ulcers [4] [8] [9] [10] [11].

\section{Aim}

The aim was to describe how high local peak pressures may be distributed over risk areas for pressure ulcers in different wheelchair settings.

\section{Methods}

\subsection{Study Group}

Data from two previous studies that included two groups of healthy individuals were further analysed to identify the location of peak pressures in seating [12] [13]. One group included elderly individuals, recruited through two pensioners' organizations in south-western Sweden, which disseminated the information and mediated contact (group A: $\mathrm{n}=40$; mean age, 75 years; range, 67 - 82 years). The other group included younger individuals who were recruited through advertising at a Swedish university in south-east Sweden (group B: $\mathrm{n}=30$; mean age, 28 years; range, 20 - 53 years) (Table 1). Inclusion criteria for group A were age between 20 and 55 years, without pain in their back, hips or pelvis and weight less than $100 \mathrm{~kg}$. Inclusion criteria for group B were age between 65 and 85 years, without pain in their back, hips or pelvis and weight less than $100 \mathrm{~kg}$. 
Table 1. Description of the study groups.

\begin{tabular}{ccccc}
\hline & Group A: age 67 - 82 & Group B: age 20 - 53 & & y value \\
\hline Gens $(\mathrm{n}=40)$ & years $(\mathrm{n}=30)$ & & \\
Women & $27(67.5)$ & $22(73)$ & $\chi^{2}=0.278$ & $0.60 \mathrm{~ns}$ \\
Men & $13(32.5)$ & $8(27)$ & & \\
Age (years), mean (min-max) & $75(67-82)$ & $28(20-53)$ & $\mathrm{t}=27.8$ & $<0.001$ \\
Weight (kg), mean (min-max) & $77.6(54-100)$ & $65(50-100)$ & $\mathrm{t}=4.53$ & $<0.001$ \\
Height (cm), mean (min-max) & $167(155-191)$ & $170(158-187)$ & $\mathrm{t}=-1.29$ & $0.20 \mathrm{~ns}$ \\
\hline
\end{tabular}

ns, not significant.

\subsection{Materials and Methods}

Two standard models of manual wheelchairs were used for the study. One wheelchair setting had an individually adjustable sling-back support attached with Velcro for modifying back support curvature; the other had a sling-back support without the Velcro for modification but with an external lumbar support. The wheelchair cushions used included one standard flat foam cushion and one shaped positioning seat cushion. The wheelchairs were set up in an upright seating position with the same seat and back angles (back seat angle $100^{\circ}$, seat angle $100^{\circ}$ ). Armrests were removed to prevent pressure loading on the armrests. The participants sat in each of two wheelchair settings for 10 minutes while the pressure was registered and documented. In addition, pelvic rotation was registered after sitting for 10 minutes.

\subsection{Test Set-Up}

Group A (elderly individuals):

Test set-up R2 A: Standard wheelchair with a standard flat foam cushion and individually adjusted back support (Velcro straps).

Test set-up R3 A: Standard wheelchair with a shaped positioning seat cushion and individually adjusted back support (Velcro straps).

Group B (younger individuals):

Test set-up R2 B: Standard wheelchair with a standard flat foam cushion and an individually adjusted back support (Velcro straps)

Test set-up R3 B: Standard wheelchair with a shaped positioning seat cushion and a fixed back support supplemented with external lumbar support (Jay ${ }^{\mathrm{TM}}$ lumbar support, Figure 1).

\subsection{Data Collection}

Interface pressure was registered using the FSA (Force Sensing Array, Vista Medical). The pressure mat was used to document peak pressures after sitting for 10 minutes [14]. The mat has been tested for validity and reliability with acceptable results, and it has been used in several previous studies [14] [15] [16]. The FSA continuously measures the mean and peak pressure of the loaded area [12] [16] [17]. 


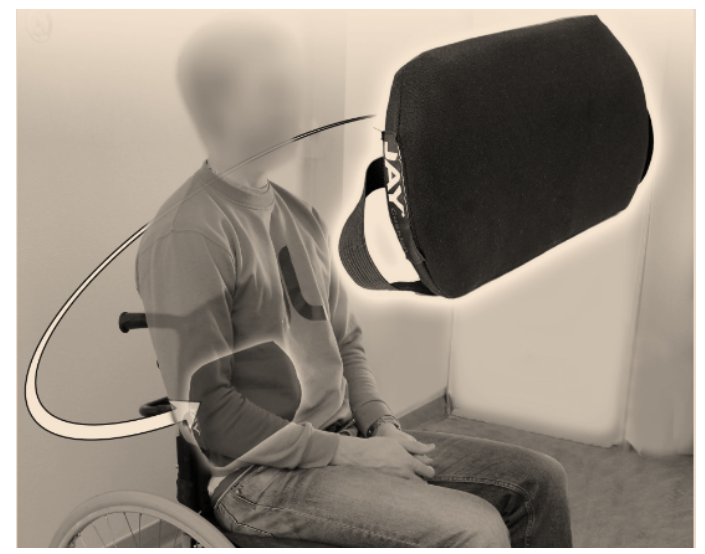

Figure 1. The lumbar support used to support the upper part of the pelvic and the lumbar spine of the participant.

Pelvic rotation was measured with a study-specific inclinometer (RodbyInnovation $\mathrm{AB}$ ). The same type of instrument has been found sufficiently valid compared with X-ray findings in earlier studies [17] [18].

\subsection{Data Analysis}

Highest peak pressures from the ischial tuberosity, trochanter and coccyx were identified and documented from existing pressure maps. Data were analysed by the authors supported by professional statisticians, using the Statistical Analysis System statistics program. Results were presented as descriptive (mean and standard deviations) as well as calculated differences between the wheelchair settings. For statistical analysis, statistical significance was determined as $p<0.05$, with a $95 \%$ confidence interval. Because no data from similar earlier studies were available, no power analysis was made to calculate for sample size.

\section{Ethical considerations}

All participants were informed about the study aim and process, that participation was voluntary and anonymous, and how the results were going to be used and presented. All participants gave informed consent before data collection. The study did not require approval from the local ethics committee because all participants were healthy individuals and the testing procedure was not expected to have any effect on any physical or psychological function.

\section{Results}

Gender, height and weight did not have a significant correlation with peak pressures $(p>0.05)$ for any of the study groups. In addition, no differences in peak pressure between the left and right sides of the seating surface were found in any of the wheelchair settings or study groups $(p>0.05)$. Thus, these results are not further reported or discussed. Nevertheless, the study groups have been reported separately because the wheelchair set-ups were slightly different and the groups differed regarding age, which is likely to affect the body composition and posture in seating. 


\subsection{Differences in Peak Pressure for Wheelchair Set-Ups and Locations per Group}

The results are presented as wheelchair set-ups R2 (standard wheelchair with standard seat cushion and individually adjusted back support) and R3 (standard wheelchair with shaped positioning seat cushion). The elderly group had individually adjusted back support with Velcro straps and the younger group had a fixed sling-back support supplemented with external lumbar support $\left(\mathrm{Jay}^{\mathrm{TM}}\right)$ placed at the upper part of the pelvis and the lumbar curve.

The result showed that the elderly had a higher peak pressure on the ischial tuberosity in wheelchair set-up R3 (the shaped seat cushion) compared to R2 (the standard cushion) $(p<0.05)$. This difference was not found in the younger group $(p=0.16)$. The peak pressure over the trochanter area was higher in R3 than R2 in both groups; $p<0.001$ in the elderly group, $p<0.01$ in the younger group (Table 2 and Table 3 ). Peak pressure over the coccyx area was higher in R3 than in R2 for the elderly group $(p<0.05)$, whereas it was lower for the younger group $(p<0.001)$ (Table 2 and Table 3$)$.

\subsection{Pelvic Rotation for Each Group and Wheelchair Set-Up}

The results indicated increased posterior pelvic rotation in R3 for the elderly group, whereas the younger group had increased posterior pelvic rotation in R2, which might explain the increased peak pressure over the coccyx in R2 for the younger group (Table 4). The difference confirms that the different set-ups were not fully comparable even though similar equipment and adjustments were used. In addition, age-related physical impairments might have had an effect on pelvic range of motion.

\subsection{Correlation between Pelvic Rotation and Localisation of Different Peak Pressures for Each Participant Group}

No significant correlation between pelvic rotation and peak pressure in wheelchair set-up R3 was found for any of the participating groups or pressure areas. Nor were there any correlations between pelvic rotation in the elderly group in wheelchair set-up R2 and ischial tuberosity, trochanter or coccyx areas. For the younger group, there was a correlation between pelvic rotation and peak pressure over the trochanter $(p<0.05)$ and coccyx $(p<0.05)$ (Table 5 and Table 6).

Table 2. Peak pressure in different areas and different wheelchair set-ups in group A.

\begin{tabular}{ccccccc}
\hline & $\begin{array}{c}\text { Peak pressure } \\
\mathrm{R} 2(\mathrm{mmHg})\end{array}$ & $\begin{array}{c}\text { Peak pressure } \\
\mathrm{R} 3(\mathrm{mmHg})\end{array}$ & $\begin{array}{c}\text { Difference } \\
(\mathrm{mmHg})\end{array}$ & $\begin{array}{c}\text { Difference } \\
(\%)\end{array}$ & $\mathrm{t}$ & $p$ value \\
\hline $\begin{array}{c}\text { Ischial tuberosity, } \\
\text { mean (SD) }\end{array}$ & $121.5(50.3)$ & $128.8(48.8)$ & $7.3(43.7)$ & $14.9(44.5)$ & 2.12 & 0.041 \\
$\begin{array}{c}\text { Trochanter, } \\
\text { mean (SD) }\end{array}$ & $79.8(31.3)$ & $129.6(39.4)$ & $49.8(37.6)$ & $78.6(70.3)$ & 7.07 & $<0.001$ \\
$\begin{array}{c}\text { Coccyx, } \\
\text { mean (SD) }\end{array}$ & $65.2(31.1)$ & $74.2(31.4)$ & $9.08(35.02)$ & $29.6(70.7)$ & 2.65 & 0.012 \\
\hline
\end{tabular}

SD, standard deviation. 
Table 3. Peak pressure for different areas and different wheelchair set-ups in group B.

\begin{tabular}{ccccccc}
\hline & $\begin{array}{c}\text { Peak pressure } \\
\text { R2 (mmHg) }\end{array}$ & $\begin{array}{c}\text { Peak pressure } \\
\text { R3 (mmHg) }\end{array}$ & $\begin{array}{c}\text { Difference } \\
(\mathrm{mmHg})\end{array}$ & $\begin{array}{c}\text { Difference } \\
(\%)\end{array}$ & $\mathrm{t}$ & $p$ value \\
\hline $\begin{array}{c}\text { Ischial tuberosity, } \\
\text { mean (SD) }\end{array}$ & $111.4(29.9)$ & $116.7(31.9)$ & $6.3(37.5)$ & $10.7(39.1)$ & 1.47 & $0.152 \mathrm{~ns}$ \\
$\begin{array}{c}\text { Trochanter, } \\
\text { mean (SD) }\end{array}$ & $71.2(15.1)$ & $88.6(28.1)$ & $13.5(29.1)$ & $19.3(34.9)$ & 2.97 & 0.006 \\
$\begin{array}{c}\text { Coccyx, } \\
\text { mean (SD) }\end{array}$ & $39.0(13.1)$ & $23.2(9.2)$ & $-16.3(12.02)$ & $-37.1(24.9)$ & -8.02 & $<0.001$ \\
\hline
\end{tabular}

ns, not significant; SD, standard deviation.

Table 4. Pelvic rotation for each group and wheelchair set-up.

\begin{tabular}{ccccccc}
\hline & $\begin{array}{c}\text { Pelvic rotation } \\
\mathrm{R} 2\left({ }^{\circ}\right)\end{array}$ & $\begin{array}{c}\text { Pelvic rotation } \\
\mathrm{R} 3\left({ }^{\circ}\right)\end{array}$ & Difference & $\begin{array}{c}\text { Difference } \\
(\%)\end{array}$ & t & $p$ value \\
\hline $\begin{array}{c}\text { Group A, } \\
\text { mean (SD) }\end{array}$ & $7.9(5.0)$ & $12.3(5.4)$ & $4.39(4.96)$ & $91.6(166.8)$ & 3.47 & 0.002 \\
$\begin{array}{c}\text { Group B, } \\
\text { mean (SD) }\end{array}$ & $10.5(4.1)$ & $6.4(5.1)$ & $-4.2(4.83)$ & $-38.8(44.3)$ & -4.64 & $<0.001$ \\
\hline
\end{tabular}

Table 5. Results from the correlation analysis for pelvic rotation and peak pressure in wheelchair set-up R2 (standard wheelchair with standard cushion and back support).

\begin{tabular}{ccccc}
\hline & \multicolumn{2}{c}{ Group A } & \multicolumn{2}{c}{ Group B } \\
\hline & rvalue & $p$ value & rvalue & $p$ value \\
\hline Ischial tuberosity & -0.020 & $0.904 \mathrm{~ns}$ & 0.088 & $0.643 \mathrm{~ns}$ \\
Trochanter & 0.070 & $0.670 \mathrm{~ns}$ & 0.414 & 0.023 \\
Coccyx & 0.253 & $0.116 \mathrm{~ns}$ & 0.398 & 0.03 \\
\hline
\end{tabular}

ns, not significant.

Table 6. Results from the correlation analysis for pelvic rotation and peak pressure in wheelchair set-up R3 (elderly with adjusted back support; younger with fixed back support and external lumbar support).

\begin{tabular}{ccccc}
\hline & \multicolumn{2}{c}{ Group A } & \multicolumn{2}{c}{ Group B } \\
\hline & rvalue & $p$ value & rvalue & $p$ value \\
\hline Ischial tuberosity & 0.169 & $0.299 \mathrm{~ns}$ & -0.187 & $0.342 \mathrm{~ns}$ \\
Trochanter & -0.186 & $0.252 \mathrm{~ns}$ & 0.111 & $0.574 \mathrm{~ns}$ \\
Coccyx & 0.040 & $0.806 \mathrm{~ns}$ & 0.043 & $0.827 \mathrm{~ns}$ \\
\hline
\end{tabular}

\section{Discussion}

A wheelchair might be seen as a relatively simple assistive device but with a substantial number of components and accessories. These components/accessories need to be individually fitted to enable comfort and function and prevent pressure ulcers. In general, an upright and functional position supported by a wheelchair with proper dimensions and with a shaped back and seat unit is 
recommended. For persons who use a wheelchair as their main seating furniture, a pressure-relieving seat cushion is often recommended due to the risk of pressure ulcers.

Studies indicate that pressure ulcers are caused by high interface pressure maintained over prolonged periods and that pressure ulcers are associated with pain, impaired quality of life, loss of functions, increased risk of dying and higher health care costs [15] [19]. Pressure ulcers can be prevented by a seat cushion that helps to distribute interface pressure over a large area with no high peak pressures over bony and sensitive areas. A study based on 232 elderly individuals sitting in a wheelchair for at least 6 hours a day indicated that a properly adjusted wheelchair and a correctly adjusted shaped positioning seat cushion resulted in significantly lower incidence of pressure ulcers at the ischial tuberosity compared with a standard cushion [19] [20]. Studies conducted on healthy individuals have indicated that the peak pressure might increase with a shaped positioning seat cushion compared with a standard cushion [21] [22]. Thus, it can be assumed that it is not only the type of seat cushion that can predict high peak pressures over different areas at risk for pressure ulcers; it is also important to try, adjust and evaluate each wheelchair and cushion individually.

The aim of this study was to describe how local peak pressures were distributed over those areas most sensitive to high pressures in seating: the ischial tuberosity, trochanter and coccyx. The study was based on data from two previous research studies in which groups of elderly and younger healthy individuals participated [21] [22]. Healthy individuals were chosen partly to reduce the risk that any underlying injuries or illnesses would affect the results. The results for the elderly and younger participants covered a large range, especially in the elderly group. However, this is not particularly surprising considering that natural aging involves a variety of bodily changes, such as reduced length and altered body composition, reduced bone and muscle mass and increased fat [9] [10] [13] [23].

In both groups, the results showed increased interface pressure over the trochanter in the shaped positioning seat cushion compared with the standard cushion. This may not come as a surprise given that the purpose of a shaped positioning seat cushion is to support the pelvis by letting the pelvis sink into a "sitting cavity", which aims to reduce pressure over the ischial tuberosity by increasing the pressure over the trochanter area, compared with a flat non-shaped seat cushion. However, the trochanter area is also at risk for pressure ulcer development and high peak pressures should thus be observed and followed over time. There were some differences between the groups. The elderly group showed increased posterior rotation in R3. This might explain the increased pressure in all three areas (ischial tuberosity, trochanter and coccyx)with the shaped positioning seat cushion compared with the standard cushion. The results for the younger group showed increased posterior rotation of the pelvis in $\mathrm{R} 2$, which could explain the increased pressure on the coccyx with the standard cushion. However, the younger group also had increased pressure on the trochanter with the shaped positioning seat cushion, but, unlike the elderly group, 
there was no increase in pressure on the ischial tuberosity and coccyx with the shaped positioning seat cushion. An explanatory factor for the difference between the groups might be that the elderly group had difficulties maintaining an upright pelvic position due to age-related stiffness and less muscle strength, which in turn might cause increased pressure at all points [22]. Another explanation for the difference is that the younger group received external and more distinct lumbar support, whereas in the elderly group, an adjustable back support was used which is less supportive.

The wheelchair is a seating unit, but it provides the opportunity for users to maintain bodily functions, prevent damage and to provide an opportunity for active life based on the individual's condition. For individuals for whom the wheelchair becomes the primary seating unit, it should be viewed as a body orthosis on wheels and should therefore be individually adjusted [7] [14]. Observing and following an individual's bodily changes and interface pressures in a wheelchair is almost impossible. This requires frequent and continuous follow-up of both the wheelchair unit and the seat accessories using valid and reliable measurement tools.

\section{Study Limitations}

The prerequisites of the two study groups differed in several aspects. Apart from age (which was planned for) weight also differed. However, weight had no correlation with peak pressure results for any of the groups, indicating that peak pressure is not dependent on weight. The wheelchair equipment differed between the groups because the wheelchair and cushion manufacturers were different. However, the wheelchairs were adjusted to the same seat and back support angles, all footrests and armrests were removed and the same type of seat cushions and back supports were used for the two different set-ups. Nevertheless, the differences between the groups might explain some of the results. Using a positioning seat cushion might require increased support for the upper part of the pelvis and the lumbar back as was given for the younger group in set-up B [7] [21] [22] [24]. This might explain the difference in pelvic rotation and peak pressure over the coccyx area between the two groups.

\section{Conclusion}

Peak pressures might be higher with a shaped cushion and individually adjusted lumbar support, whereby the person gets support for a more upright pelvic position, which in turn facilitates breathing and a number of different activities. The goal to support a more upright position is of great relevance; however risk factors such as high local pressures should be carefully followed over time. It is necessary to follow up interface pressure especially for the elderly, the fragile and the population with spinal cord injuries in whom mobility is impaired, skin is less elastic, subcutaneous fat is reduced, blood vessels are impaired and sensory perception is decreased [8] [9] [10] [11]. 


\section{Acknowledgements}

The authors would like to thank all participants and all personal helping us with the data collection.

\section{Conflicts of Interest}

The authors declare no conflicts of interest regarding the publication of this paper.

\section{References}

[1] Hjälpmedelsinstitutet, Ä. (2010) Äldres hälsa, funktionsnedsättning, boende och hjälpmedel [Health, Disability, Living and Assistive Devices for the Elderly]. Stockholm, Swedish.

[2] Nysam. Hjälpmedelsverksamhet-Nyckeltal (2016) [Keyratios]. Stockholm 2016. Swedish. http://nysam.com/report/form

[3] Sveriges Kommuner och Landsting. Trycksår (2011) Åtgärder för att förebygga [Pressuresores Prevention Methods]. Ljungbergs Tryckeri, Stockholm, Swedish. http://webbutik.skl.se/sv/artiklar/trycksar-atgarder-for-att-forebygga.html

[4] Stenius, M. (2016) Trycksår-Med livetsominsats [Pressure Sores-With Life as an Effort]. Rehab Station, Stockholm, Sweden.

[5] European Pressure Ulcer Advisory Panel and National Pressure Ulcer Advisory Panel (2009) Treatment of Pressure Ulcers: Quick Reference Guide. National Pressure Ulcer Advisory Panel, Washington DC.

[6] Grimby, A. and Grimby, G., Eds. (2001) Åldrandets Villkor [Aging Conditions]. Studentlitteratur, Lund, Sweden.

[7] Engström, B. (1993) Ergonomics Wheelchair and Positioning. A Book of Principles based on Experience from the Field. Posturalis Books, Sweden.

[8] Stockton, L., Gebhardt, K. and Clark, M. (2009) Seating and Pressure Ulcers: Clinical Practice Guideline. Journal of Tissue Viability, 18, 98-108.

https://doi.org/10.1016/j.jtv.2009.09.001

[9] Ferrarin, M., Andreoni, G. and Pedotti, A. (2000) Comparative Biomechanical Evaluation of Different Wheelchair Seat Cushions. The Journal of Rehabilitation Research and Development, 37, 315-324.

[10] Gefen, A. (2014) Tissue Changes in Patients Following Spinal Cord Injury and Implications for Wheelchair Cushions and Tissue Loading: A Literature Review. Ostomy Wound Management, 60, 34-45.

[11] Shoham, N., Levy, A., Kopplin, K., et al. (2015) Contoured Foam Cushions Cannot Provide Long-Term Protection against Pressure-Ulcers for Individuals with a Spinal Cord Injury: Modeling Studies. Advances in Skin and Wound Care, 28, 303-316. https://doi.org/10.1097/01.ASW.0000465300.99194.27

[12] Ferguson, P.M. and Cardi, M. (1993) Prototype Development and Comparative Evaluation of Wheelchair Pressure Mapping System. Assistive Technology, 5, 78-91. https://doi.org/10.1080/10400435.1993.10132213

[13] Bagger, S.D., Ed. (2006) Det goda åldrandet [Goodaging]. Carlssons Bokförlag, Stockholm, Sweden.

[14] Ward, D.E. (1994) Prescriptive Seating for Wheeled Mobility. Health Wealth International, Kansas City. 
[15] Crawford, S.A., Strain, B., Gregg, B., et al. (2005) An Investigation of the Impact of the Force Sensing Array Pressure Mapping System on the Clinical Judgement of Occupational Therapists. Clinical Rehabilitation, 19, 224-231. https://doi.org/10.1191/0269215505cr826oa

[16] Stinson, M., Porter, A. and Eakin, P. (2002) Measuring Interface Pressure: A Laboratory-Based Investigation into the Effects of Repositioning and Sitting. American Journal of Occupational Therapy, 56, 185-190. https://doi.org/10.5014/ajot.56.2.185

[17] Crowell, R.D., Cummings, G.S., Walker, J.R., et al. (1994) Intratester and Intertester Reliability and Validity of Measures of Innominate Bone Inclination. Journal of Orthopaedic and Sports Physical Therapy, 20, 88-96.

https://doi.org/10.2519/jospt.1994.20.2.88

[18] Samuelsson, K., Tropp, H., Nylander, E., et al. (2004) The Effect of Rear-Wheel Position on Seating Ergonomics and Mobility Efficiency in Wheelchair Users with Spinal Cord Injuries: A Pilot Study. The Journal of Rehabilitation Research and Development, 41, 65-74. https://doi.org/10.1682/JRRD.2004.01.0065

[19] Brienza, D., Kelsey, S., Karg, P., et al. (2010) A Randomized Clinical Trial on Preventing Pressure Ulcers with Wheelchair Seat Cushions. Journal of the American Geriatrics Society, 58, 2308-2314. https://doi.org/10.1111/j.1532-5415.2010.03168.x

[20] Brienza, D., Karg, P., Geyer, M., Kelsey, S. and Trefler, E. (2001) The Relationship between Pressure Ulcer Incidence and Buttock-Seat Cushion Interface Pressure in At-Risk Elderly Wheelchair Users. Archives of Physical Medicine and Rehabilitation Home Mobile RSS Feeds, 82, 529-533. https://doi.org/10.1053/apmr.2001.21854

[21] Samuelsson, K., Björk, M., Erdugan, A.M., et al. (2009) The Effect of Shaped Wheelchair Cushion and Lumbar Supports on Under-Seat Pressure, Comfort, and Pelvic Rotation. Disability and Rehabilitation: Assistive Technology, 4, 329-336.

[22] Timm, M. and Samuelsson, K. (2006) Wheelchair Seating: A Study on Healthy Elderly. Scandinavian Journal of Occupational Therapy, 23, 458-466. https://doi.org/10.3109/11038128.2016.1152297

[23] Saxon, S., Etten, M. and Perkins, E. (2010) Physical Change and Aging. Springer Publishing Company, New York.

[24] Kobara, K., Eguchi, A., Watanabe, S. and Shinkoda, K. (2008) The Influence of the Distance between the Backrest of a Chair and the Position of Pelvis on the Maximum Pressure on the Ischium and Estimated Shear Force. Disability and Rehabilitation: Assistive Technology, 3, 285-291. 